The 49th Annual Conference of the International Association of School Librarianship

The 24th International Forum on Research on School Librarianship

July $12-16,2021$

Prasanna Ranaweera

University of Colombo, Sri Lanka

prasanna@nilis.cmb.ac.lk

\title{
Reading Promotion Programme on literature appreciation among the young adults in Sri Lankan Schools Conducted by the Ministry of Education
}

\begin{abstract}
A pilot reading program as an action research project was introduced by The National Institute of Library \& Information Sciences (NILIS) in order to inculcate reading appreciation among young adults in Sri Lankan schools. A sample of 25 school libraries from the Maho Educational Zone was selected for the research study. Each grade nine student studying in the above-selected twenty-five schools was given a young adult literature book to be read within fourteen days, after which the student was required to prepare a portfolio based on the book. The school librarians marked the students' portfolio pieces, and this practice was continued up to the beginning of the third semester, using various literary genres. The students completed the given task within the specified period. According to the students' final portfolio evaluation, it was seen that they had gradually developed their competencies under the affective domain based on the above curriculum. Eventually, the Ministry of Education implemented the above program among all the junior and senior secondary schools in Sri Lanka as "Books are the Best Friends" with the assistance of NILIS.

Keywords: reading programs; school libraries; young adult literature
\end{abstract}

\section{Introduction}

When conducting various reading programs, school librarians need to be aware of the concept of teaching reading to primary, secondary, and upper secondary levels in the General Education system of Sri Lanka. The first step, the anatomy of reading, is the exposition stage of that scenario. Regarding this point, the inner parts of a letter to book, words, phrase, sentence, 
paragraph, and chapter, and skills related to the above stages need to be identified in order to conduct a successful reading program, based on reading for survival, for primary grade students. After the primary level, students enter grade six to continue their junior secondary and senior secondary education up to grade thirteen. During this stage, students read various subject-related books to enhance their knowledge. As a result, students develop the left side of the brain (cognitive side), such as facts, theories, principles, mathematics skills, language skills, etc. Simultaneously, students need to develop the right side of the brain, (affective domain) such as love, affection, rhythm, dancing, singing songs, etc. using fiction material in reading for pleasure (Hedican, 2013). As a net result of developing these two types of reading activities, a student can become a balanced person, which is the final aim of the general education system.

\section{Statement of the Research Problem}

To be a balanced person, the student needs to develop the concepts of both sides of their brain. However, according to the report of the National Education Commission (Sedere et al., 2016), students need to face three highly competitive examinations: the scholarship examination in grade five, G.C.E O/L examination in grade eleven, and G.C.E.A/L examination in grade thirteen to qualify for admission to the university, during their school career. As a result of this situation, both teachers and parents are engaged in the exam-oriented education system in order to enhance the students' subject knowledge, and do not motivate them toward reading for pleasure, such as reading fiction, poetry, and drama. Therefore, students become reluctant to involve themselves in reading fiction material which develops the skills related to the affective domain, or the right

side of the brain. Further, school librarians employ various informal methods when promoting literature appreciation programs for young adults, instead of a formal method. To remedy this situation, the researchers proposed introducing a pilot program as a school-wide action research project in order to discover a formal method to promote reading for pleasure for the young adults in the Sri Lankan Education System.

\section{Literature review}

The Sri Lankan school library collection is divided into two main categories: the nonfiction and fiction collection. The nonfiction collection or subject-related books on mathematics, science, history, etc., which develop reading for subject knowledge, are categorized under the Dewey 
Decimal classification system or a color code method in the school libraries. On the other hand, the fiction collection is categorized basically as novels (F1), short stories (F2), and translations (F3) to promote reading for pleasure, under children's and young adult literature.

According to the Sri Lankan context, the period from the beginning of puberty to the legal adult age is considered the young adult stage in Sri Lanka. Therefore, approximately between the age of 12 to 18 (grade 7 to grade 13), a student is considered a young adult and is in the young adult literature stage. Joan F. Kaywell (2000) formulated several definitions for young adults, including ages between 11 and 16, between 10 and 21, between 12 and 22, and grades 6-12. During this period, the child becomes a young adult and finally grows into a legal adult, passing through three substages, such as pre, middle, and post-adolescence, as a transition period in life. Thus, the young adult stage is very crucial for a human being because of the gradual development of the physical, cognitive, emotional, social, and cultural aspects of life.

When we talk about literature, philosophers have emphasized that "books are our best friends" because related reading provides valuable guidelines to solve problems and to make proper decisions with regard to the personal, professional, and pedagogical life (3P's) of a person. However, a student of the young adult stage has only a personal and pedagogical life (2P's) and reading for pleasure helps them to develop their personality traits and to become a balanced student.

Firstly, the student needs to identify the genres of young adult literature in order to reach this destination. According to Bucher and Hinton (2014), the genres of young adult literature are categorized as follows: Contemporary Realistic Fiction, Adventure, Mystery, Humor, Science Fiction, Fantasy, Horror, Historical Fiction Biography, Nonfiction/information, Poetry, Drama, Short Stories, Comic Books, Graphic Novels, Picture Books, and Magazines. Each fiction genre has its own unique style and rhythm, which allows it to communicate the relevant message to the adolescent. Therefore, reading not only selected genres, but reading all the genres is beneficial to absorb the given messages which will contribute toward building a balanced personality.

After identifying the diversity of genres related to young adult literature, teenagers need to acquire proper awareness about the elements of literature required for inculcating literary appreciation, such as characters, setting, point of view, theme, plot, etc. This will enable them to 
reach the upper stages of their learning pathway as deep learners. Within these stages higher-order thinking skills (creative, critical, and abstract thinking) can be gradually developed toward the making of a balanced person.

Finally, as a result of the gradual development of higher-order thinking skills, young adults will easily enter the independent learning stage, and be able to provide their portfolio reflections regarding their fiction reading, which will demonstrate their metacognitive knowledge.

Therefore, this theoretical framework which comprises identifying literary genres, awareness about literary elements, analyzing plot diagrams, and writing reflections, will be helpful in developing a formal method for literature appreciation.

\section{Methodology}

In order to introduce the pilot reading program with the school-wide action research, twenty-five school libraries were selected from among one hundred and twenty-five schools in the Maho Educational Zone as a purposive sample. Next, the grade nine students, librarians, language teachers, and principals were selected from each school. To begin, a thirty-hour workshop related to young adult literature was conducted by the researchers as an awareness program, for the selected school librarians, teachers, and principals, within the first term of the school calendar.

After completing the orientation program, the young adult literature collection of each school library was divided into 15 genres and arranged on separate shelves during the school vacation period of the first term.

At the beginning of the second term each teacher, librarian, and language teacher conducted a ten-hour young adult literature orientation program, for selected grade nine students, for a period of two weeks. As a result, the students acquired the related knowledge and skills required to continue with the research program. First, each student was given a young adult literature book to read within 14 days. During this time period, the students were required to do their homework based on the given book, including bibliographic details, literary elements, plot diagram, and the students' reflections as a piece of the portfolio. After 14 days, the librarians collected the students' portfolio pieces with the given young adult literature book and provided another genre 
of young adult literature to the students for further reading. Meanwhile, each school language teacher and librarian marked the students' portfolio pieces according to the prepared evaluation criteria and continued this program up to the end of the semester. During the action research time period the internal and external monitoring and evaluation of the research program was conducted by each school principal and the researchers, respectively. Finally, the students completed their reading, based on ten young adult literature books related to the various genres, and the teacher librarians assessed the students' portfolios related to their literature appreciation. Also, each school teacher, librarian, language teacher, and principal submitted their prepared school action research reports for evaluation.

\section{Findings}

After completing a thirty-hour orientation program based on young adult literature, the selected school teachers, librarians and principals prepared a curriculum for the grade nine students of the sample, as a ten-hour literary introduction program. At this point a short syllabus on intended learning outcomes and teaching methodologies was prepared as a teaching-learning module based on the following subtopics:

1. Bibliographic detail

2. Genre of young adult literature

3. Literary elements

4. Plot diagram

5. Reflection

Meanwhile, the teachers and librarians introduced a systematic method to categorize and arrange the fiction collection of their libraries under the genres of young adult literature. Apart from that, they identified and finalized the various stages of this reading promotion program, which is to be conducted for the students, as follows.

1. Each student selects a monitor exercise book for report writing.

2. Librarians prepare a guideline booklet and distribute it to all the students. 
3. Provide an opportunity for students to select any young adult literature book from the arranged shelves in the library.

4. Within the given time duration (fortnight) students read their novels and write down their first portfolio pieces using given instructions on their monitor exercise book.

5. After a fortnight, each student submits their given novel and written monitor exercise book to the librarian and takes a book of another genre from the bookshelves for the second round of their reading program. During the first week of this procedure, each teacher and librarian marks each student's written monitor exercise book and first portfolio piece, using the marking scheme given below. After that, the librarian returns the monitor exercise book to the student to write their second portfolio piece according to the second novel, as a formative evaluation. In addition, the parents of the student submit a brief report regarding the student's behavior during the fortnight of reading activities together with the student's portfolio pieces.

1. Bibliographic detail

2. Name the type of Genre

3. Describe literary elements

4. Drawing and explaining each stage of the plot diagram

5. After reading the novel, students' reflection

Total
10 marks

05 marks

25 marks

30 marks

30 marks

100 marks

Accordingly, the students understood their strengths and weaknesses, and their parents also recognized the children's achievement levels and provided further instructions to them.

6. According to the above procedure, the program was continued up to the end of the second vacation of the school system (three and a half months). Finally, the students submitted their completed portfolios for the summative evaluation.

\section{Discussion}

When considering the above research program, four stages can be identified as follows. 
1. Thirty-hour orientation program for selected teachers, teacher librarians and principals of the sample

2. Identifying and categorizing the genres of the young adult literature collection of each school library program

3. Conducting the three and a half month reading promotion program based on grade nine students.

4. Writing an action research report program for each school, related to its completed reading program.

When analyzing the formative and summative reflective writings, and oral presentations of the staff orientation program, it was perceived that they had learned literature as a subject during their general and higher education school period, but had never learned this kind of formal and practical approach related to young adult literature. They stated that they were able to identify their previous mistakes when introducing reading activities to the young adults, and now they have a clear pathway to conduct reading promotion programs for teenagers in their families and schools.

Secondly, after organizing the collection of teenage novels in the first term vacation of each school, the librarians stated that earlier they had arranged their fiction section according to the basic classification scheme, such as novels (F1), short stories (F2), and translations (F3). In such a situation the students did not have proper awareness related to the various genres of young adult literature and generally they had selected and read books from only one or two genres from the fiction section. As a result, they could not absorb the genuine taste of young adult literature and the net result was that it had a negative effect on their emotional and intellectual development. In contrast, the researchers had displayed fifteen genres (historical, science fiction, fantasy, etc.) within the fiction shelves and students could easily locate books on various genres, and the library staff could monitor and evaluate their searching behavior effectively and efficiently.

The main objective of this research was to engage the students in a reading promotion program over three and a half months. According to the results of the students' portfolios it was seen that they had gradually developed their language skills, handwriting, reading, writing skills and 
communication skills related to the cognitive domain. When analyzing the class teachers' and parents' reflection reports, it shows that the students had gradually increased their behavioral skills under the affective domain.

Finally, each school research team, librarian, language teacher, and principal submitted their action reports to the zonal education office and evaluated them as a panel method. Twenty-five schools participated in this program and all of them submitted their research reports. According to their findings, students gradually developed their concepts related to the right side of the brain using this formal reading promotion program related to young adult literature.

\section{Conclusion}

After submission of the action research reports, the library subject coordinating director of the zonal education office organized a one-day conference for all school librarians in the "Maho" Educational Zone, based on the results of this research, as an awareness program. Thereafter, the above librarians launched a reading promotion program for grade six students as a "Supper Six Program" for junior secondary schools in the above Zone. Because of the high rate of achievement, the researchers presented this pilot program to the Minister of Education, in order to introduce it as a national level reading promotion program. Finally, the Education Ministry accepted the program and introduced it to young adult students in the island-wide school system of Sri Lanka as "Books Are the Best Friends" (Kalana Mithuru Poth Sumithuru) based on a national level circular issued by the Ministry of Education of Sri Lanka.

\section{References}

Bucher, K. T., \& Hinton, K. V. (2014). Young adult literature: Exploration, evaluation, and appreciation. Pearson.

Hedican, J. (2013). A right brain approach to reading intervention. [Master's thesis, Vancouver Island University] VIURRSpace. http://hdl.handle.net/10613/2502.

Kaywell, J. F. (2000). Adolescent literature as a complement to the classics. Norwood, MA: Christopher-Gordon Publishers.

Sedere, U. M., Jayasinghe-Mudalige, U. K., \& Karunaratne, S. (2016). Study on evaluation \& 
the assessment system in General Education in Sri Lanka. National Education Commission. http://nec.gov.lk/wp-content/uploads/2016/04/3-Final-.pdf.

Wanasundara, N.P. (2004). Handbook for school librarians in Sri Lanka with practical suggestions. Godage Publishers. 